A United States Department of Commerce Technology Administration

National Institute of Standards and Technology

NISTIR 5026

Thermal Hydraulic Tests of a Liquid Hydrogen Cold Neutron Source
J.D. Siegwarth
D.A. Olson
M.A. Lewis
J.M. Rowe
R.E. Williams
P. Kopetka

$Q C$

100

.456

45026 



\section{Thermal Hydraulic Tests of a Liquid Hydrogen Cold Neutron Source}

J.D. Siegwarth

D.A. Olson

M.A. Lewis

J.M. Rowe

R.E. Williams

P. Kopetka

Process Measurements Division

Chemical Science and Technology Laboratory

National Institute of Standards and Technology

Boulder, Colorado 80303-3328

July 1994

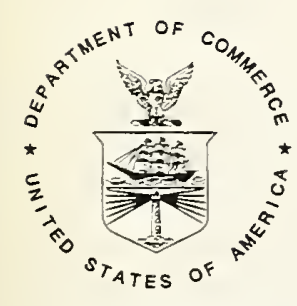

U.S. DEPARTMENT OF COMMERCE, Ronald H. Brown, Secretary TECHNOLOGY ADMINISTRATION, Mary L. Good, Under Secretary for Technology NATIONAL INSTITUTE OF STANDARDS AND TECHNOLOGY, Arati Prabhakar, Director 



\title{
Thermal Hydraulic Tests of a Liquid Hydrogen Cold Neutron Source
}

\author{
J.D. Siegwarth, D.A. Olson and M. A. Lewis \\ Process Measurements Division \\ Chemical Science and Technology Laboratory \\ National Institute of Standards and Technology \\ Boulder, CO \\ J. M. Rowe, R. E. Williams and P. Kopetka \\ Reactor Radiation Division \\ Materials Science and Engineering Laboratory \\ National Institute of Standards and Technology \\ Gaithersburg, Maryland
}

\begin{abstract}
We have built and tested a simplified full scale model of the planned liquid hydrogen moderator for the cold neutron source of the NIST reactor. The heat load to the liquid hydrogen will be removed to an external refrigerator by means of a thermosyphon. Our experiments showed that this system could be filled, would operate stably, and the gas volume in the moderator chamber would not exceed 20 percent. Results of the tests suggested some improvements to the original designs. The circulation of liquid hydrogen proved to be self-regulating even when the available liquid inflow rate was sufficient to flood the vapor line.
\end{abstract}

Keywords: cold neutrons; cold source; liquid hydrogen; moderator; neutrons; nuclear reactor; thermosyphon

\section{Introduction}

Cold neutrons, those with wavelengths greater than $0.4 \mathrm{~nm}$, are useful for a wide range of studies of solid state material, analytical chemistry, and fundamental physics. The cold neutron flux from a nuclear reactor can be enhanced by passing the neutron beam through a moderator cooled to cryogenic temperatures. The National Institute of Standards and Technology (NIST) reactor (NBSR) presently uses $\mathrm{D}_{2} \mathrm{O}$ ice at $40 \mathrm{~K}$ to enhance the cold neutron flux. By replacing the $\mathrm{D}_{2} \mathrm{O}$ ice with liquid hydrogen $\left(\mathrm{LH}_{2}\right)$ at $20 \mathrm{~K}$, designers expect the moderator system to substantially increase the cold neutron flux. To verify stable operation of the designed system, a full scale model of the $\mathrm{LH}_{2}$ portion of this system was built and tested at NIST Boulder (NISTB). This paper describes the test results of the simplified full-scale model.

The objectives of the tests at NIST-B were to demonstrate that the moderator chamber could be filled and maintained at the boiling temperature of $\mathrm{LH}_{2}$ with a void fraction of less than $20 \%$ and that the boiling would not cause surges or fluctuations in the amount of liquid contained in the chamber. The moderator chamber of the test system was made of glass to visually observe the boiling behavior. Instrumentation was limited to that required to measure two temperatures, the system pressure and the moderator chamber weight. The phenomena observed during the tests 
had to be interpreted with these few measurements since neither time nor resources permitted the installation of more instrumentation. Modifications were made to the design during the tests to improve the system performance.

\section{The Proposed NBSR Moderator Design}

The initial design of the $\mathrm{LH}_{2}$ moderator chamber for the NBSR is illustrated in figure 1. It consists of a $20 \mathrm{~mm}$ wide spherical annulus $320 \mathrm{~mm}$ in outside diameter filled with $\mathrm{LH}_{2}$. The annulus is modified by the inclusion of a $200 \mathrm{~mm}$ diameter beam exit hole. The expected $0.8 \mathrm{~kW}$ radiation heat load on the moderator chamber will be removed by allowing the $\mathrm{LH}_{2}$ to boil near its normal boiling point of $20 \mathrm{~K}$. The resulting vapor is recondensed outside the reactor shielding and the liquid returned to the moderator chamber.

The NBSR cold source system will operate as a thermosyphon. Such a system has been studied by Hoffman and coworkers [1-4]. The system consists of the moderator chamber, a heat exchanger condenser to reliquefy the hydrogen vapor from the moderator, and liquid and vapor lines connecting the chamber and condenser. The NBSR design is diagrammed in figure 2 . The liquid and vapor lines extend horizontally in the beam tube from the moderator chamber to the reactor face, then vertically to the condenser. The vertical section must be long enough to provide sufficient liquid head to drive the circulation loop. This head must equal the pressure loss due to the flow in both the liquid and vapor lines. The condenser is cooled by helium gas from a helium refrigerator.

The volume of the NBSR moderator system containing hydrogen must be closed for safety. A quantity of $\mathrm{H}_{2}$ sufficient to fill the moderator chamber without flooding the vapor return line with $\mathrm{LH}_{2}$ will be introduced into the closed system. The ballast tank attached to the system must be capable of holding the entire $\mathrm{H}_{2}$ inventory at a pressure below $500 \mathrm{kPa}$ should the entire system warm to ambient temperature.

The liquid inlet and the vapor return line will extend about $3 \mathrm{~m}$ horizontally then $1.85 \mathrm{~m}$ vertically from the chamber to the condenser. The vapor line $(28.6 \mathrm{~mm}$ diameter by $0.9 \mathrm{~mm}$ wall thickness) runs coaxially around the liquid line $(12.7 \mathrm{~mm}$ diameter by $0.9 \mathrm{~mm}$ wall thickness) in the NBSR design. This simplifies the assembly of the liquid and vapor lines and their attendant vacuum and helium jackets, and keeps their cross section small in the narrow confines of the beam tube. Since the vapor line exits the moderator chamber horizontally and near to the liquid surface in the moderator chamber, the dome is designed to serve as a liquidvapor separator (fig. 1). The liquid accelerated through the nozzle is deflected by the dome into the trough at the base of the dome. The liquid drains through a hole back into the moderator chamber while the vapor exits through the vapor return line. In the initial design, the incoming liquid line discharged into this circular trough. Our tests indicated that the liquid line should be discharged into the bottom of the moderator chamber, for reasons described below.

The heat input due to radiation absorption in the moderator chamber structure is a function of the total mass of aluminum used to fabricate it. To reduce this mass, the thickness of the inner shell of the annulus will be only $0.5 \mathrm{~mm}$. This shell is too thin to sustain the $500 \mathrm{kPa}$ ambient 
pressure, so the inside volume of the inner ball will connect at its bottom to the annular space through a tube $6 \mathrm{~mm}$ diameter by $25 \mathrm{~mm}$ high. This connection eliminates the pressure difference across the inner wall. The radiation heating of both the inner shell and its contents maintains gas in the inner ball, preventing liquid from entering at steady state operating conditions.

Control of the neutron moderator system will be based on the measurement of the vapor pressure of the $\mathrm{H}_{2}$. The vapor pressure will control the refrigeration rate to the condenser. Assuming the system already contains $\mathrm{H}_{2}$ gas, the thermosyphon should start shortly after $\mathrm{LH}_{2}$ begins to condense and the moderator chamber starts to fill with liquid. The thermosyphon operating range should extend, in terms of the quantity of gas in the system, from the condition where the chamber contains a small amount of liquid to the condition where the liquid partially floods the vapor return line. The liquid automatically equilibrates at the level in the liquid fill line of sufficient height to drive the circulation of the liquid and gas. If the heating rate should increase or the cooling rate decrease more rapidly than the condenser can respond, the chamber liquid content will decrease to provide the gas needed to increase the system pressure. This decrease may disturb the neutron flux somewhat but should not interrupt the operation of the thermosyphon. A decrease in heat to the moderator or an increase in refrigeration faster than the control system response could interrupt the operation of the thermosyphon.

Thermosyphons often exhibit oscillatory behavior, depending on the geometric design and the operating conditions (Greif) [5]. Oscillating masses of $\mathrm{LH}_{2}$ in the annular shell would probably cause an undesirable time varying neutron flux and could be detrimental to the safe operation of the cold source if the oscillations became too violent. The annular shell design differs enough from the cylindrical tank design of Hoffman [1-4] that it is difficult to predict its performance a priori.

\section{NIST-B Full Scale Test Apparatus}

A full scale model of the proposed NBSR $\mathrm{LH}_{2}$ moderator was built at NIST-B to examine the performance of the design. The test system is illustrated in figure 3. A helium refrigerator was unavailable, so the refrigeration source used was $\mathrm{LH}_{2}$ supplied from a 2001 Dewar. The radiation heat input was simulated by resistance heaters wound around the inner ball in an approximately uniform surface density. The vapor generated by the heating was vented to the atmosphere after returning to the supply Dewar rather than recondensed. The $\mathrm{LH}_{2}$ was pumped by a submerged centrifugal pump into a constant head cup at the top end of the liquid inlet line. The pump operated at full capacity during most of the testing and the excess pumped liquid spilled over the rim of the cup back to the supply Dewar. A flow control valve was placed in the pump outlet line to throttle the flow into the constant head cup to that just sufficient to replenish the moderator chamber.

The primary differences between the NBSR design and the NIST-B test system resulted from the different refrigeration sources. The pressure in the NIST-B moderator chamber was fixed by relief valves and the vapor pressure of the liquid in the Dewar and could not fluctuate. The NBSR moderator system pressure could fluctuate if the refrigeration source is not tightly 
controlled by vapor pressure. Instead of the intrinsic control of the liquid head driving the circulation, the NIST-B test system was driven by a constant head when the pump discharge was not throttled since the cup always overflowed. The NIST-B test system might at least test the ability of the NBSR system to cool the chamber even if stable operation proved difficult to achieve by throttling the pump.

Commercially available 12 and 221 spherical boiling flasks were used to form the inner and outer spherical shells of the glass moderator chamber shown in figure 4 . The resulting annular gap exceeded that of the NBSR design but the difficulty of working with such a large and complicated glass chamber precluded any attempt to resize the flasks. Like the NBSR moderator chamber design, a tube interconnected the interior of the inner ball and the annulus. The radiation heat load to the chamber was simulated by a resistance heater consisting of a flat nichrome ribbon wound loosely around the inner ball as shown in figure 4 . The heater area was made large enough so that at $2 \mathrm{~kW}$ input power the heat flux was no more than one quarter the critical heat flux required to cause film boiling (the heat flux in the NBSR moderator chamber walls will be well below critical).

The moderator chamber was continuously weighed in the NIST-B test system to determine the void volume. The chamber was suspended from an electronic balance whose weigh cell was placed in the insulating vacuum approximately above the geometric center of the chamber. The moderator chamber was supported at a second point, the pivot point of the flex joint in the vapor return line (fig. 3). This support point was displaced about $46 \mathrm{~cm}$ horizontally from the vertical line through the geometric center of the chamber. The use of a single flex joint in the vapor line simplified the design and assembly but complicated the weighing procedure as described below.

The empty weight of the chamber was counterbalanced so that the balance supported a $3 \mathrm{~kg}$ load. The current supplying the restoring force of the balance was 0 at this load. This minimized any heating effects in the force coil that might have arisen from the reduced cooling in the vacuum.

When the liquid line emptied at the top of the chamber, as shown in figure 4, neither the line nor its contents contributed to the balance reading. The fill line was supported by the vapor line upstream of the hinge point and cantilevered out over the trough in the dome without touching the portion of the vapor line attached to the chamber. The plastic tubes, used in later tests to extend the liquid feed line to the lower part of the annulus, did contact the chamber and contributed some to the balance reading. Neither the contact between the chamber and the fill tube nor the electrical lead connections adversely affected the accuracy or repeatability of the weighing of the chamber. The masses of interest were differences which eliminated any error caused by the tube contacts. A calibrated weight could be placed on and off the balance to test both accuracy and repeatability over the measurement range.

A balance reading for the beginning of the chamber could not be obtained. The chamber position shifted with temperature as the system cooled. The forces due to the contact between the plastic section of the fill line and chamber also changed. A correction for the mass of the 
gas in the chamber could not be determined since liquid began to collect before all the chamber had cooled to $20 \mathrm{~K}$. The balance reading for zero fill had to be determined from the annular volume. The volume of the annulus was determined by filling the annulus with roomtemperature water and weighing. The annular volume of the glass moderator chamber measured by this method was 6.7551 , about 1.751 more than that of the NBSR chamber. This volume would contain approximately $482 \mathrm{~g}$ of saturated $\mathrm{LH}_{2}$ at $85 \mathrm{kPa}$ with zero heat input to the chamber.

The glass moderator chamber allowed the boiling behavior of the $\mathrm{LH}_{2}$ to be observed and photographed through windows in the vacuum jacket. The temperature of the vapor line near the moderator chamber $\left(\mathrm{T}_{1}\right)$ was measured to provide information on the cooling rate of the moderator chamber. The temperature of the head cup $\left(\mathrm{T}_{2}\right)$ was measured to detect when the pump was discharging liquid into the head cup. A point level sensor, used to show when the Dewar was filled with $\mathrm{LH}_{2}$, also served as an indicator that the head cup was overflowing. In the final test, the Dewar pressure reading was read and recorded along with the weight and temperature readings.

We did eight separate tests of the performance of the moderator. These tests are summarized in table 1. For the first five tests, the liquid fill line ended above the annulus and emptied into

Table 1. Summary of experimental conditions and results

\begin{tabular}{||c|l|l|l|l||}
\hline Test & $\begin{array}{l}\text { Condition of } \\
\text { vacuum }\end{array}$ & $\begin{array}{l}\text { Location of liquid } \\
\text { discharge }\end{array}$ & $\begin{array}{l}\text { Height of } \\
\text { head cup } \\
(\mathrm{mm})\end{array}$ & \multicolumn{1}{|c|}{ Major result } \\
\hline 1 & Poor $^{\mathrm{a}}$ & Top of nozzle & 70 & Filled once \\
\hline 2 & Poor & Top of nozzle & 70 & Did not fill \\
\hline 3 & Poor & Top of nozzle & 70 & Filled four times \\
\hline 4 & Marginal & Top of nozzle & 70 & $\begin{array}{l}\text { Filled twice, stable } \\
\text { operation on second }\end{array}$ \\
\hline 5 & Poor & Top of nozzle & 70 & Filled once \\
\hline 6 & Good & $\begin{array}{l}\text { Bottom of annulus, } \\
\text { corrugated tube }\end{array}$ & 150 & Did not fill \\
\hline 7 & Good & $\begin{array}{l}\text { Bottom of Annulus, } \\
\text { Smooth Tube }\end{array}$ & 150 & $\begin{array}{l}\text { Filled, Stable } \\
\text { Operation }\end{array}$ \\
\hline 8 & Good & $\begin{array}{l}\text { Bottom of Annulus, } \\
\text { Smooth Tube }\end{array}$ & 150 & $\begin{array}{l}\text { Filled, Stable } \\
\text { Operation }\end{array}$ \\
\hline \hline
\end{tabular}

a. Greater than about $10^{-7}$ bar

b. Below $10^{-8}$ bar 
the trough at the top of the chamber as shown in figure 4. For Test 6 , the fill line was extended to the bottom of the annular shell by adding a $9.6 \mathrm{~mm}$ ID section of corrugated plastic tubing to the liquid line as shown in figure 3 . This tubing extended from near the hinged joint in the vapor line to the bottom of the moderator chamber. For Tests 7 and 8 , a $9.6 \mathrm{~mm}$ ID flexible plastic tube with smooth interior and exterior surfaces replaced the corrugated tube and the head cup height was more than doubled, increasing the overall driving head by about $8 \mathrm{~cm}$. Prior to Test 7, the liquid fill line was made of the same size aluminum tubing that will be used in the NBSR moderator system. For later tests, it was changed to stainless steel for convenience of assembly. The vapor return line was the same for both configurations, stainless steel tube with soft soldered connections. For the first tests, the $3 \mathrm{~m}$ long fill line section from the bottom of the vertical line to the moderator chamber was about horizontal. The vertical section of the liquid line was shortened by about $3 \mathrm{~cm}$ after Test 6 to assure some down slope to the line.

\section{Initial Cool Down and Liquid Fill}

To cool the moderator chamber and fill it with $\mathrm{LH}_{2}$, the sensible heat of the chamber and lines must be removed. Also, the heat leaking to the chamber and transfer lines by conduction and radiation during the cool down must be removed. The heat leak increases with decreasing temperature. One important performance issue for the system was how well it would cool from ambient to operating temperature.

The inlet line and return vapor lines constitute a coaxial heat exchanger that hampers the cool down process. At the start of a cool down, mostly gas flows in the inner "liquid" side. For an efficient heat exchange between the coaxial tubes, the cool down will be slower since the driving force for the inflow is fixed by the head provided by the $\mathrm{LH}_{2}$ inlet line. If the increasing heat leak becomes equal to the refrigeration introduced by the incoming cold hydrogen, the system will not cool further. If the system cools enough that liquid passes through the inlet side of the counterflow exchanger while an equal mass of gas exits on the other side, the heat exchanger is unbalanced and the cooling power is increased by the amount of the latent heat of the liquid.

The NBSR cold neutron source will be cooled to $\mathrm{LH}_{2}$ temperature before the reactor is started. Therefore, the moderator chamber of the test apparatus was cooled for all eight tests without power to the internal heater. During the first five tests, the test apparatus had a cold leak (poor vacuum) from the moderator system into the vacuum jacket which was difficult to locate and repair. A leak sealant was tried, but was only partially successful because the leak was a crack in the glass of the lowest heater lead seal. For Tests 1,2,3, and 5, the heat leak to the moderator chamber alone may have been as much as $200 \mathrm{~W}$ based on hydrogen boil off rates. The conduction heat leak to the vapor line was estimated to be as much as $250 \mathrm{~W}$. The thermal radiation to the vapor line was probably no more than $10 \mathrm{~W}$. The heat radiated to the vapor line was small compared to that of the glass of the moderator chamber because of the lower emissivity. The tests conducted when the vacuum leak was present provided information on the maximum heat leak that could be tolerated while still cooling and filling the moderator chamber.

The heat leak as a function of liquid level in the annulus could be measured by measuring the rate of change of the chamber weight with time when the chamber contained $\mathrm{LH}_{2}$ without 
electrical heating or liquid inflow. For Test 4 , the heat leak rate measured $110 \mathrm{~W}$. The leak sealant apparently reduced the leak temporarily for this test. Before test 6 , the leak was found and repaired. For Tests 6,7 , and 8, the insulating vacuum was good and the heat leak dropped to $60 \mathrm{~W}$. This remaining heat leak was mainly radiation to the chamber and conduction down the leads and supports.

When the heat leak to the chamber exceeded $110 \mathrm{~W}$, but was less than $200 \mathrm{~W}$, filling the chamber was possible but unreliable. Filling would sometimes start but then stop spontaneously and not restart. In Tests 2 and 5, the chamber never filled, even though some liquid entered the annulus. The chamber filled once during Test 1 , four times during Test 3 , and twice during Test 4. In these tests the filling would not restart unless the chamber almost completely emptied of $\mathrm{LH}_{2}$. Variations in the cold leak caused by the attempt to close the vacuum leak with a sealant is the suspected cause of these variations in the fill behavior.

The cool down and liquid filling lasted 80 to $90 \mathrm{~min}$. during Test 4, when the liquid line emptied into the top and the heat leak was $110 \mathrm{~W}$. Cool down and filling required about $70 \mathrm{~min}$. for Tests 7 and 8 after the liquid line was extended to the bottom of the annulus and the heat leak was reduced to $60 \mathrm{~W}$. The fill took 2 hrs. for Test 1 , probably because of the larger cold leak during that test.

Cooling proved to be sensitive to the interior surface of the fill line. The vapor line temperature $\mathrm{T}_{1}$ and the moderator chamber weights as a function of time during cool down for Tests 6 and 7 are shown in Figure 5. The only difference between the two tests was the type of plastic tube used to extend the fill line from the pivot point to the bottom of the chamber as shown in Figure 3. For Test 6 , the plastic tube was corrugated; for Test 7 , the tube was smooth inside. Not only was the rate of cool down for Test 6 much smaller, but after 10 hrs. the cooling essentially stopped when the vapor line temperature reached $115 \mathrm{~K}$.

Visual observations during cool downs of the moderator chamber showed the cause of the cooling failure of Test 6 . The corrugated tube was semi transparent so the behavior of the $\mathrm{LH}_{2}$ during the fill could be seen. When the tube wall was smooth, droplets, supported by the gas stream, could be seen entering the chamber during initial cool down when the vapor line temperature was still well above $200 \mathrm{~K}$. In contrast, when the corrugated tube extended the fill line to the bottom of the moderator chamber, drops could be seen in the entrance end of the tube, but no liquid reached the bottom of the chamber even when the vapor line temperature dropped to $115 \mathrm{~K}$. The droplets apparently fell into the corrugations and evaporated. The corrugated tube must have improved the efficiency of the counterflow exchanger to the degree that the cooling capacity of the incoming cold gas was no more than the heat leak to the chamber at $115 \mathrm{~K}$.

In the smooth tube, the liquid droplets were entrained and blown into the chamber by the rapidly moving gas streams such that they seldom contacted the tube walls. Apparently, the corrugations of the tube wall reduced or eliminated this entrainment allowing the liquid to be trapped in the corrugations. The droplets never reached the discharge end of the fill line and the chamber would not cool. When the inlet and vent lines form a counter flow heat exchanger, 
the unbalance of the heat exchanger introduced by the entrained liquid droplets is necessary to provide sufficient refrigeration to cool the moderator chamber to $\mathrm{LH}_{2}$ temperatures.

\section{Thermosyphon Restart Following Loss of Refrigeration}

A momentary failure of the helium refrigerator could stop the inflow of liquid to the moderator. The inflow, if interrupted, should be restarted quickly before the moderator chamber empties of $\mathrm{LH}_{2}$. If the moderator chamber empties and warms the reactor would have to be shut down to restart the thermosyphon to the moderator chamber. Restart of the reactor becomes problematical toward the end of a fuel cycle because of the build up of xenon.

To determine how well the moderator system restarted, we performed a number of tests where we stopped the inflow of liquid and attempted to restart it again. During the first five tests, after the chamber filled we interrupted the inflow usually by shutting down the pump. Even with no electric power to the heaters, the liquid inflow would not restart until the chamber was nearly empty of $\mathrm{LH}_{2}$. We believe that the failure of the circulation to restart after the inflow had been interrupted was caused by the back flow of boil off gas in the liquid line; the gas was generated from the radiation and conduction heat leaks.

After the liquid inflow stopped and the $\mathrm{LH}_{2}$ level in the chamber dropped below the outlet of the liquid line, the boil off gas could flow through both the vapor and liquid lines. The vapor velocity in the liquid line was high enough to inhibit the reestablishment of a liquid column in the liquid line. A small amount of liquid was able to make its way down the liquid line to the moderator chamber during this time, but the flow was too low to refill the chamber. Because the glass moderator shell had a low thermal conductivity, the heat leak to the $\mathrm{LH}_{2}$, hence the boil off rate, would fall as the $\mathrm{LH}_{2}$ level dropped. Once the chamber was nearly empty the gas flow subsided enough that refill could start.

After Test 5 we located and repaired the leak in the lower heater lead seal. After Test 6 we extended the liquid discharge to the bottom of the annulus with a smooth tube, and the height of the constant head cup was increased from $70 \mathrm{~mm}$ to $150 \mathrm{~mm}$. We extended the fill line to the bottom of the moderator chamber in an attempt to stop the back flow of $\mathrm{H}_{2}$ vapor, at least until the chamber emptied of $\mathrm{LH}_{2}$. With these three modifications, restart was much better for Test 7.

After the moderator chamber was filled for Test 7, the pump was stopped for $25 \mathrm{~min}$. with no power to the heater. The liquid inflow started immediately upon restarting the pump. The flow was then stopped with power applied to the heater. For liquid inflow stopped at 1 and $3 \mathrm{~min}$. each at 250 and $350 \mathrm{~W}$, the flow immediately restarted when the pump was restarted. At 450 $\mathrm{W}$, the flow restarted immediately after $1 \mathrm{~min}$. of pump stoppage but would not restart after 3 min. The liquid inflow may have restarted once at $800 \mathrm{~W}$ after a momentary stop of the pump. Liquid inflow did restart at $800 \mathrm{~W}$ when the flow was stopped for about $1 / 2 \mathrm{~min}$. by closing the flow control valve. Even though the ability to restart was improved by the modifications prior to Test 7 , reliable restart only occurred at low heater power and after short periods without liquid inflow. 
For any power input where steady state operation could be obtained, the temperature $T_{1}$ of the vapor return line was $20 \mathrm{~K}$ (the boiling point) until the liquid inflow stopped (see fig. 6). Then the departing vapor was superheated above the boiling point. When this superheat was less than $10 \mathrm{~K}$, the chamber began to refill immediately as the weight curve of figure 6 shows. When the superheat exceeded $10 \mathrm{~K}$ refill would not start immediately upon restart of the pump. Restart did occur once for a $18 \mathrm{~K}$ superheat at $350 \mathrm{~W}$ power when the inflow was stopped for $5 \mathrm{~min}$. The inflow in this case did not restart immediately with restart of the pump.

We explain the inability of the thermosyphon to restart for certain conditions during Test 7 as follows. When the liquid level in the chamber dropped below the top of the inner ball (see fFig. 4) the heater wires were exposed and the venting gas was superheated as it passed by these wires. The elevation of the horizontal section of the liquid line was only about $5 \mathrm{~cm}$ above the liquid level when the heater became exposed. The pressure drop in the vapor return line was certainly sufficient to maintain liquid in the horizontal section of the fill line. The superheated gas venting from the chamber would exchange heat with the static liquid in the fill line, causing the liquid to boil. The gas generated must back flow in the liquid line, forestalling the refilling in the vertical section of the liquid line from the head cup. Because some of the heat transferred from the gas is absorbed by the latent heat of the liquid, the back flow of gas in the extended inlet line was probably less than the back flow of gas when the inlet line terminated at the top of the moderator chamber. Thus, restart was improved when the liquid inlet line terminated below the liquid level in the chamber, but was still not as good as might be expected had the inlet line been thermally insulated from the vapor return line.

Design changes between Tests 4 and 7 of the increased cup height, the improvement of the vacuum insulation, and the extension of the fill line to the chamber bottom all could have contributed to the improvement of the restart performance. Although tests did not separate the influences of these changes on restart, we believe the extension of the liquid fill line to the bottom of the ball probably produced the most improvement, followed by the improvement of the vacuum. The increase in the height of the head cup probably contributed little if any to the improvement.

Several differences in design and operating conditions between the NBSR and the NIST-B test system all favor easier restart for the NBSR. Unlike the test system, the heat generated in the NBSR moderator chamber will decrease with decreasing liquid level because there will be less mass to absorb energy from reactor radiation. Part of the heat generated in the aluminum walls will conduct through the wall to the liquid. Both of these differences decrease the superheat of the venting gas and should improve restart. The condenser heat exchanger will have considerable thermal inertia so that a momentary interruption of the refrigerator will not result in an immediate cessation of liquid inflow. Restart of $\mathrm{LH}_{2}$ circulation may occur at the anticipated $800 \mathrm{~W}$ heat load to the NBSR moderator chamber. Decreasing the thermal contact of the liquid and vapor lines (which may not be feasible) should improve restart.

\section{Steady State Operation of the Thermosyphon}

After filling the test system with $\mathrm{LH}_{2}$ with no heat dissipation, the thermosyphon must be 
"turned on" at the desired heat load. It took several tests before we learned how to operate the thermosyphon stably with heat applied. In the early tests, when we first attempted to control the rate of liquid delivery (as we assumed necessary to keep the chamber from flooding), we closed the valve too much which interrupted the liquid inflow. As discussed previously, once the inflow stopped, it would not restart reliably until the chamber emptied. Each time the annulus filled, the inner sphere of the moderator chamber filled to about 35 to 40 percent also. Since the inner sphere supplied $\mathrm{LH}_{2}$ to the annulus until it emptied, stable operation could not be assumed until the inner sphere emptied.

Stable operation was first achieved on Test 4 . Since previous attempts to achieve stable operation by adjusting the liquid delivery had failed, we left the flow control valve wide open and the pump running after the chamber filled. The heater power was set to $0.5 \mathrm{~kW}$. Unexpectedly, without our adjusting the liquid flow control valve, the balance reading stabilized to a constant value. The balance reading (which is approximately the $\mathrm{LH}_{2}$ mass) and heater power for this test are shown in figure 7. The temperature of the vapor line thermometer held steady at the $\mathrm{LH}_{2}$ saturation temperature for the duration of this test. For the next $80 \mathrm{~min}$., as we changed the heating from 0.5 to $1.6 \mathrm{~kW}$, the balance reading stabilized quickly at each different power level with the exception of $1.6 \mathrm{~kW}$. At $1.6 \mathrm{~kW}$, the chamber gradually lost mass; however, we observed continuous inflow of liquid into the chamber. The refrigeration available from the incoming $\mathrm{LH}_{2}$ was obviously less than the $1.7 \mathrm{~kW}$ total heat input introduced by the heater $(1.6 \mathrm{~kW})$ plus the heat leak $(0.1 \mathrm{~kW}$ estimated). At a power of $1.5 \mathrm{~kW}(1.6 \mathrm{~kW}$ total) the annulus stayed filled. When we reduced the heating to $0.5 \mathrm{~kW}$, the chamber weight immediately stabilized to the balance reading previously obtained at $0.5 \mathrm{~kW}$.

Steady operation was also attained in Tests 7 and 8 (prior to which we had modified the vent and fill lines). The balance reading and power as a function of time for Test 7 are shown in figure 8. As in Test 4 , the balance reading changed quickly to a new value with each change in heater power.

During Test 8 , the moderator chamber was operated at a total heat input of $2.1 \mathrm{~kW}$ then $2.3 \mathrm{~kW}$ for a total of $7 \mathrm{~min}$. without upsetting the inflow. This was a significant improvement over the $1.7 \mathrm{~kW}$ maximum obtained for Test 4 . The estimated conduction heat leak to the chamber and vapor return line may have been reduced by as much as 0.2 to $0.4 \mathrm{~kW}$ due to the improved vacuum. Both the improved vacuum and the modified transfer lines could contribute significantly to the higher stable power level achieved in Test 7. Also, the inner sphere had not completely emptied during these tests. The fact that the two rather different configurations of the cold neutron source represented by Tests 4 and 7 show stable and repeatable operation suggests that the stability may exist over a wide range of conditions.

We speculate that the mechanism controlling the liquid inflow is related to conditions in the vapor return line, where we observed a two-phase liquid-vapor mixture. The increased friction factor of two-phase flow plus the increased density probably increased the pressure drop in the vapor line enough to limit the inflow of liquid. The pressure drop in the vapor line could also have been increased by accumulation of liquid in the horizontal section of the vapor line, being held there by the return vapor flow. The fluctuation of the reading of the point level sensor in 
the Dewar meant that throughout the variation of the heater power, the cup continued to spill liquid, indicating the pump was delivering more liquid than could flow to the moderator chamber. The pump could supply up to an estimated $8 \mathrm{~g} / \mathrm{s}$ flow to the head cup, which if all were delivered to the moderator could absorb over $3.6 \mathrm{~kW}$.

An internal mechanism that would permit stable operation after sufficient hydrogen was present to flood the vapor line was not anticipated when the system was designed. Active control was assumed necessary for the NIST-B test apparatus. The existence of a stable operating state with liquid flooding the vapor line means that the NBSR system could be slightly overfilled to assure steady-state operation. The amount of gas in the system need not be carefully adjusted to exactly fill the chamber and the fill line to the required heights.

If operation with a partially filled inlet line should prove unstable, the NBSR system could be operated in the constant inlet head configuration of the NIST-B system by adding more $\mathrm{H}_{2}$ to the inventory to bring the liquid level up into the bottom of the condenser. This assumes the bottom of the condenser has a large liquid surface area.

Time and resource constraints prevented operating the test apparatus with the inlet liquid head in the inlet line, that is, by throttling the pump delivery down to the exact flow required to maintain a full chamber.

\section{Visual Observations of Boiling the Moderator Annulus}

The hydrogen vapor produced bubbles in the annulus that reduced the mass of hydrogen in the chamber. The volume of the vapor in the chamber depends not only on operating pressure and the power input to the liquid, but also on the rate of rise of the bubbles to the liquid surface. Confining the liquid to a narrow annular gap could result in liquid being blown out of the annulus by rapid gas expansion below the liquid surface. The actual moderator chamber design is optimized if the annulus contains at least 80 percent liquid by volume, or no more than 20 percent void fraction.

A uniform distribution of hydrogen mass in the annular shell is required to provide the highest possible slow neutron flux. Visual observations for Tests 4,7 , and 8 showed a uniform distribution of bubbles in a horizontal plane intersecting the annulus. There appeared to be a continuous increase in the vapor concentration in the vertical direction in the annulus as expected. However, during steady-state operation, there was no horizontal interface in the annulus (if present, there would be two-phase flow in the lower region and vapor in the upper region). The entire annular region was filled with two-phase flow. In the nozzle (fig. 1), we could see an interface with mostly vapor above and two-phase flow below. This interface fell in the nozzle as the heating (and vapor generation) increased. The only time the interface penetrated into the annular region was in Test 4 with heating greater than $1700 \mathrm{~W}$ (the liquid was discharged into the trough around the nozzle in Test 4). At this power the interface fell with time, indicating there was insufficient liquid delivery to hold a steady liquid fraction in the annulus. With liquid discharge changed to the bottom of the annulus, we were able to dissipate over $2200 \mathrm{~W}$ into $\mathrm{LH}_{2}$ in the annulus with no interface in the annulus. 
There were also no discernable time-dependent spatial variations of void within the annulus. That is, we did not see certain regions within the annulus oscillate between low vapor fraction and high vapor fraction. If spatial variations occurred, they could have been masked in the weight measurement if the total weight were constant. The bubbles generated in the annulus appeared to rise in a spiral about the vertical axis of the ball, making about one-eighth to onefourth of a revolution as they rose from bottom to top. The dome appeared to be supplying some liquid-vapor separation. Within the dome we could see liquid drops rising above the interface and striking the top of the dome, then draining back into the trough as a film along the outside of the dome. The observed boiling behavior is desirable for neutron moderation, as the lack of spatial or temporal variations in the void fraction should produce a steady neutron flux.

The rise time of the bubbles from the bottom to the top of the chamber was on the order of a second. The bubble sizes were on the order of $1 \mathrm{~cm}$. Peebles and Garber [6] classify bubble behavior into four regions based on the Reynolds number of the rising bubble. For these conditions, the Reynolds number is on the order of 27000 , which places the bubble velocity in region 4 , where the bubble velocity is independent of bubble size. Peebles and Garber's work was based on experimental results with single bubbles and fluids of higher density, viscosity and surface tension than $\mathrm{LH}_{2}$, and thus may not necessarily apply to the bubbles in the moderator chamber.

\section{Moderator Mass as a Function of Power}

In figure 9 we plot the balance reading as a function of total power for Tests 4 and 7 . The total power is the electrical heating plus the heat leak rate (measured by the rate of weight decrease in the absence of liquid inflow and electrical heating). These balance readings have been adjusted for the zero offset but not for calibration changes due to differences in the lever arm about the pivot point.

To calculate the void fraction from the balance measurements, the data must be corrected for lever arm effects. The center of mass of the $\mathrm{LH}_{2}$ and the balance suspension are at different horizontal distances from the pivot point of the vapor line flex connection. The asymmetry of the chamber due to the beam exit hole, for example, moves the center of mass of the $\mathrm{LH}_{2}$ out to a longer lever arm about the pivot point than the lever arm of the balance. Lever arm corrections add an estimated additional $33 \mathrm{~g}$ or 6.8 percent to the balance reading when the chamber is filled with $\mathrm{LH}_{2}$ liquid (zero heat input). The $482 \mathrm{~g}$ of the liquid in the full chamber at $85 \mathrm{kPa}$ would have read an estimated $515 \mathrm{~g}$ on the tared balance. When the chamber was heated the two- phase masses would also read 6.8 percent high, if we assume an axially symmetric bubble distribution which did not shift the center of mass.

A zero shift was present because the balance reading could not tared with the chamber at $20 \mathrm{~K}$ and containing no liquid hydrogen. The balance reading at zero fill must be subtracted to determine the void fraction. The balance reading at zero fill was obtained by fitting curves to the uncorrected data. These curves were extrapolated back to zero power. The balance reading for zero fill was obtained by subtracting $515 \mathrm{~g}$ from the balance reading at zero power. Since the zero shift affects the balance reading equally at all powers, the balance reading at zero fill 
was subtracted from the balance reading at each power setting to obtain the fitted curves of figure 9. That the zero offset was entirely a zero shift and not caused by calibration shifts in the balance was determined by periodically placing a $374.4 \mathrm{~g}$ reference weight on the balance. The difference in the balance reading with and without the reference weight always agreed with the mass of the reference weight within about $\pm 0.2 \mathrm{~g}$. The repeatability of this reading demonstrates that the heater leads and fill line did not introduce any hysteresis in the weight measurements.

Correcting for lever arm effects, the $\mathrm{LH}_{2}$ masses are 6.4 percent less than the balance readings shown in figure 9. Other than the slightly different curvature of the lines, the Test 7 results are similar to Test 4 . The differences in curvature may be the result of the changes made to the test system between Test 4 and Test 7 . The void fraction for Tests 4 and 7 is shown in Figure 10. The curvature of void fraction versus heater power also differs for the two tests. Recall that inlet and vent line changes were made between Test 4 and Tests 7 and 8 .

These curves should slightly overestimate the void fraction, because the liquid level in the dome decreased as the power increased. A decrease of liquid in the dome should not decease the ability of the moderator chamber to slow neutrons, thus should not be included in the void fraction determination. The mass change associated with a $\mathrm{LH}_{2}$ level change from the top to the bottom of the dome was about $16 \mathrm{~g}$.

The calculated radiation heat load to the NBSR moderator chamber is $800 \mathrm{~W}$. From figure 10 , at $800 \mathrm{~W}$ power input, the void fraction in the test chamber due to the vapor in the annulus was 10 to 12 percent. At a vapor pressure of $85 \mathrm{kPa}$ the density of the gas in the bubbles was so much less than the liquid density that the mass decrease was also 10 to 12 percent. The above values for the void fraction is based on the annular volume of the chamber of the test apparatus, 6.755 l. The NBSR chamber will have a 26 percent smaller annular gap and contain only 51 . The mass of the gas generated by heating the annulus is independent of the liquid volume of the annulus. Since the boiling behavior of the test chamber remained unchanged to a heat input of $2.3 \mathrm{~kW}$, it seems reasonable to assume that the boiling behavior at $1 \mathrm{~kW}$ would remain unchanged if the annular gap were reduced by 26 percent. If the boiling behavior is unaltered by shrinking the annular gap, then the volume occupied by the gas generated should be unchanged by this decrease in the annular gap. As a result, the NBSR void fractions will be 35 percent greater than the measured void fractions under the same conditions. From figure 10, the test chamber at $85 \mathrm{kPa}$ could operate up to $1600 \mathrm{~W}$ before the void fraction exceeded 20 percent. The NBSR cold source would exceed the 20 percent void limit at $1050 \mathrm{~W}$ at $85 \mathrm{kPa}$. For this reason, attempts were made to measure and model the void fraction as a function of pressure.

\section{Change of Moderator Mass with System Pressure}

During Test 8 , we attempted to measure the change of mass resulting from an increase in the operating pressure of the system. Increasing the pressure shrinks the gas volume, thus decreasing the void fraction. However, the total mass of $\mathrm{LH}_{2}$ in the annulus rather than void fraction is the important parameter for neutron moderation, and the void fraction is not the only 
parameter affected by a pressure increase. Since the hydrogen remains saturated as the pressure increases, both liquid density and latent heat decrease. The mass of $\mathrm{LH}_{2}$ in the annulus is decreased by the decreases in both the liquid density and latent heat. The mass change with pressure is also a function of the bubble velocity, which determines how long an evolved bubble remains in the annular volume. If we assume the results of Peebles and Garber [6] apply, the bubble velocity should be independent of bubble size. Their expression for bubble velocity contains the ratio of surface tension to liquid density to the one-fourth power which introduces pressure dependence.

We first attempted to measure the variation of the $\mathrm{LH}_{2}$ mass in the chamber with pressure. For the first attempt, we recorded the balance reading as the system pressure increased between 85 to $125 \mathrm{kPa}$ at $860 \mathrm{~W}$ total heat. This measurement failed because the liquid level in the inner ball also increased as the pressure increased. We then attempted the measurement with the pressure decreasing slowly, again setting $860 \mathrm{~W}$ input power. This proved difficult because of the tendency of the pump to cavitate as the Dewar pressure decreased. The results of this test are shown in figure 11. The pump shut down briefly during this measurement resulting in the two groups of data, one group at pressures above $120 \mathrm{kPa}$ and the other at pressures below 115 $\mathrm{kPa}$. The mass change as a function of pressure is about $0.62 \mathrm{~g} / \mathrm{kPa}$ for the linear fit shown in figure 11. The data scatter is large.

The inner ball of the NBSR moderator will contain primarily parahydrogen whose scattering cross section is small relative to orthohydrogen. Any change of chamber mass due to changes in the quantity of parahydrogen should be excluded because of its small scattering cross section. A linear correction of $0.16 \mathrm{~g} / \mathrm{kPa}$ for the change of vapor mass in the inner ball was applied which reduced the rate of annular mass change to about $0.46 \mathrm{~g} / \mathrm{kPa}(3.2 \mathrm{~g} / \mathrm{psi})$.

Using the data of Tests 7 and 8 , we can extrapolate the results to estimate the void fraction at $152 \mathrm{kPa}$ and $860 \mathrm{~W}$ of heating (this is a possible operating point for the NBSR). At $85 \mathrm{kPa}$, the mass drops from $482 \mathrm{~g}$ for no heating to $423 \mathrm{~g}$ with $860 \mathrm{~W}$ of total heat input, a $59 \mathrm{~g}$ decrease (about 12.5 percent). Increasing the pressure from 85 to $152 \mathrm{kPa}(0.85$ to $1.5 \mathrm{~atm})$ at $860 \mathrm{~W}$ would cause a mass increase of $30.8 \mathrm{~g}$ for a total of $454 \mathrm{~g}$, using the linear data correlation from Test 8 of $0.46 \mathrm{~g} / \mathrm{kPa}$. For comparison, the mass of the liquid filled chamber (zero heat in) would be $466 \mathrm{~g}$ at a vapor pressure of $152 \mathrm{kPa}$ (no heating). This means the void fraction would be only 2.6 percent at $152 \mathrm{kPa}$ vapor pressure. However, the amount of bubbles observed at $860 \mathrm{~W}$ and elevated pressure does not support the void fraction being that low. The change of mass with pressure obtained from figure 11 is likely too high, or perhaps it can not be extrapolated beyond $125 \mathrm{kPa}$. We speculate that during the pressure decrease of test 8 , the liquid level in the inner ball did not remain constant.

We calculated the effect of pressure on the moderator hydrogen mass using hydrogen properties and the assumption that bubble velocities in $\mathrm{LH}_{2}$ are independent of size hence pressure. This is shown in figure 12 for this simple model. The mass $m$ in the annulus of volume $V$ at a vapor pressure $\mathrm{P}$ is the sum of the mass of gas in the void volume plus the mass of the liquid and can be written 


$$
m(P)=V \cdot\left[\alpha(P) \cdot \rho_{g}(P)+(1-\alpha(P)) \cdot \rho_{1}(P)\right],
$$

where $\alpha$ is the gas void fraction, $\rho_{\mathrm{g}}$ is the gas density and $\rho_{1}$ is the liquid density. Changes in the operating pressure changes the gas volume by changing the gas density, the latent heat of vaporization $h_{f g}$ and the bubble rise velocity $v$. The vapor volume decreases with increasing $P$, but the latent heat decreases with increasing $P$ which increases the gas fraction because more $\mathrm{LH}_{2}$ must vaporize to remove the same heat load. The bubble velocity can also change with $\mathrm{P}$. When we combine these effects, $\alpha$ at some P is related to $\alpha$ at $85 \mathrm{kPa}$, the pressure at which we measured the void fraction, by

$$
\alpha(P)=\alpha(85) \cdot\left[\rho_{g}(85) \cdot h_{f g}(85) \cdot v(85)\right] /\left[\rho_{g}(P) \cdot h_{f g}(P) \cdot v(P)\right] .
$$

The densities and heats of vaporization can be obtained from published fluid properties. If the bubble velocity is independent of $\mathrm{P}, \mathrm{v}(85) / \mathrm{v}(\mathrm{P})=1$. When the test system was operating at $85 \mathrm{kPa}$ and $0.86 \mathrm{~kW}$ total power input, $\alpha(85)=0.125$ maximum from the curves of figure 9 .

The mass as a function of pressure at constant bubble velocity is maximum at about $150 \mathrm{kPa}$, figure 12. The decrease in vapor volume is less than the decrease in liquid density at higher pressures. The measured pressure dependence is plotted in figure 12 so that the linear extrapolation intersects the model curve at $85 \mathrm{kPa}$. The gas volume as a function of pressure predicted by the model is plotted as a percentage of the total annular volume.

The model predicts 7.6 percent void at $152 \mathrm{kPa}$. This is considerably larger than the 2.6 percent estimated from the Test 7 and Test 8 results. The model predicts that increasing the pressure to increase the hydrogen mass succeeds only over a limited pressure range. For a constant bubble velocity, the increase in mass predicted by the model is less than $10 \mathrm{~g}$ or 2.5 percent. However, the bubble velocity decreases by about 3.5 percent as the pressure increases from 85 to $150 \mathrm{kPa}$ according to Peebles and Garber [6]. Their results were derived from measurements of the rise of small air bubble populations in various ambient liquids which may not apply to the single component boiling hydrogen system with its much lower density and much larger bubble population. If their relationship can be applied to $\mathrm{LH}_{2}$, then the possible gain in moderator mass is somewhat less than 2.5 percent.

The bubble velocity as a function of saturation pressure in $\mathrm{LH}_{2}$ could be measured by placing a heated object in a closed $\mathrm{LH}_{2}$ vessel and measuring bubble velocities as a function of vapor pressure when a heat pulse is applied to the object. These data could be used to improve the mass as a function of pressure model. Such an experiment was outside of the scope of this project.

A similar analysis of the 51 moderator chamber shows a broad maximum in hydrogen mass between 150 and $200 \mathrm{kPa}$ with an $800 \mathrm{~W}$ heat load. As a result, an operating range of 110 to $150 \mathrm{kPa}$ has been chosen for the cold source, with void fractions of 14 to 11 percent, respectively. 


\section{Conclusions}

The tests of the NBSR moderator system design carried out with the NIST-B test apparatus indicate that the proposed NBSR $\mathrm{LH}_{2}$ moderator system is feasible. The NIST-B liquid hydrogen moderator tests suggest that the void fraction will be below the upper permissible limit of $20 \%$ at the heat input anticipated. The test system boiled steadily without surges at heat inputs up to at least $2.1 \mathrm{~kW}$. The steady-state tests also showed that the liquid inflow was controlled by some mechanism in the vent line. Thus, the circulation in the thermosyphon is not threatened by flooding in the vapor line. The NBSR moderator could be operated in the same mode as the NIST-B test system by adding sufficient $\mathrm{H}_{2}$ to raise the $\mathrm{LH}_{2}$ level into the bottom of the condenser. Our tests did not establish whether stable operation could be achieved when the vapor line does not provide the flow controlling mechanism. The NBSR system behavior might also differ from that obtained for the NIST-B moderator system should the feedback control of the condenser pressure have a slow response so the system pressure varies.

Filling, restarting the fill, and the maximum heat input with stable operation may have improved when the liquid line was extended to the bottom of the moderator chamber. This cannot be unequivocally asserted from these tests because the vacuum in the insulating jacket was improved at the same time as the fill geometry was changed. Time and resource constraints precluded a comparison of top and bottom liquid inlet in the absence of vacuum leaks to the insulating jacket. A reduction of the heat transfer between the liquid and vent lines should improve the fill and restart performance.

Results of attempts to measure the effect of pressure on void volume contained a lot of uncertainty due to the presence of the internal volume connected to the annulus. A simple model of the pressure effect suggests the mass of hydrogen contained in the moderator chamber can be increased slightly by increasing the operating pressure. No significant increase in mass should be expected above about $150 \mathrm{kPa}$. 
The authors thank Eric Marquardt for his assistance with the instrumentation and glass blower Ray Allen for building the glass moderator chamber.

\section{References}

1. Hoffmann, H. "Experimental Investigations of Heat Transfer Behavior of a Horizontally Arranged Cylindrical Cold Neutron Source in a Vaporizing Deuterium Flow", Proc. 10th Int. Cryo. Eng. Conf., pp. 390-93, Helsinki (1984).

2. Hoffmann, H. and Astruc, J.M. "Experimental Investigations of the Fluid Dynamics of a Thermal Syphon with Vaporizing Deuterium for a Horizontally Arranged Cylindrical Cold Neutron Source", Proc. Cryo. Eng. Conf., pp. 462-65, Helsinki (1984).

3. Hoffmann, H. "Natural Convection Cooling of a Cold Neutron Source with Vaporizing Deuterium at Temperatures of $25 \mathrm{~K}$ ", Natural Convection: Fundamentals and Applications, S. Kakac, W. Aung, R. Viskanta, eds., Hemisphere Publishing Corp., New York, pp. 1140-51 (1985).

4. Hoffmann, H. "The Natural Convection Cooling with Vaporized Deuterium for the Horizontally Arranged Cold Neutron Source at HFR-Grenoble", International Workshop on Cold Neutron Sources, pp. 395-404, Los Alamos (March 1990).

5. Greif, R. "Natural Convection Loops", J. Heat Trans. 110:1243-58; (1988).

6. Peebles, F.N., Garber, H.J., "Studies on the Motion of Gas Bubbles in Liquids", Chem. Engr. Prog. 49:88-97; (1953). 


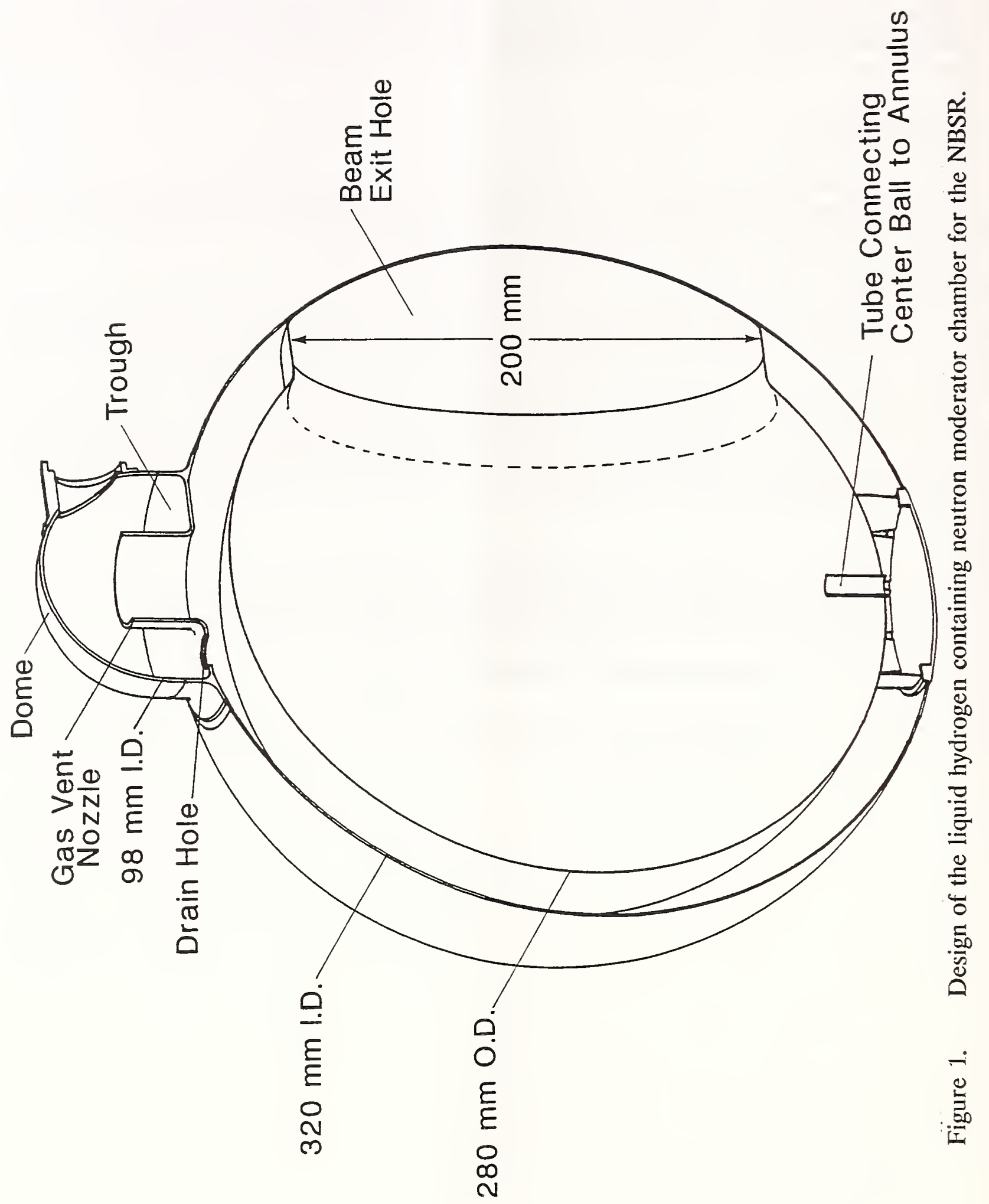




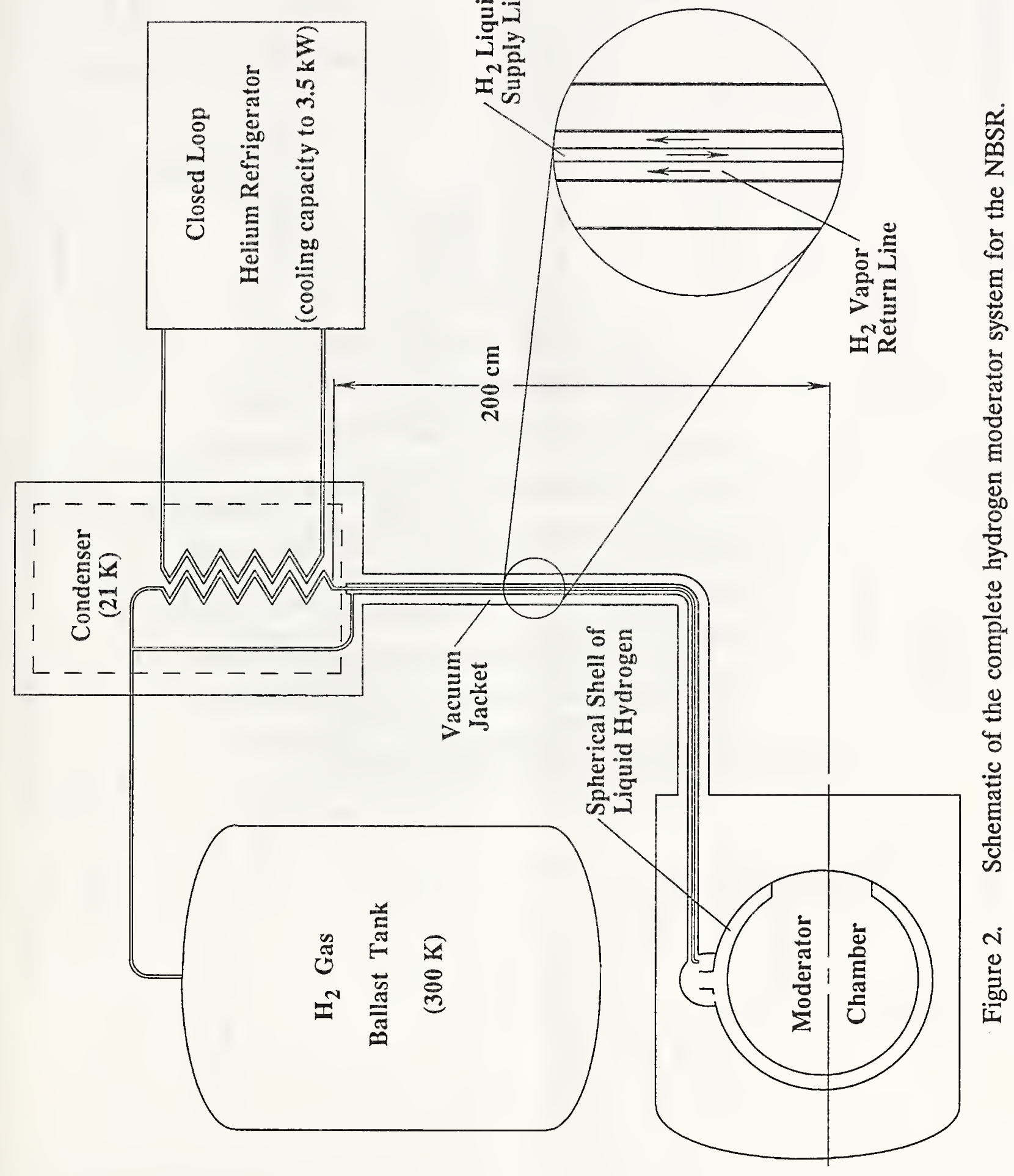




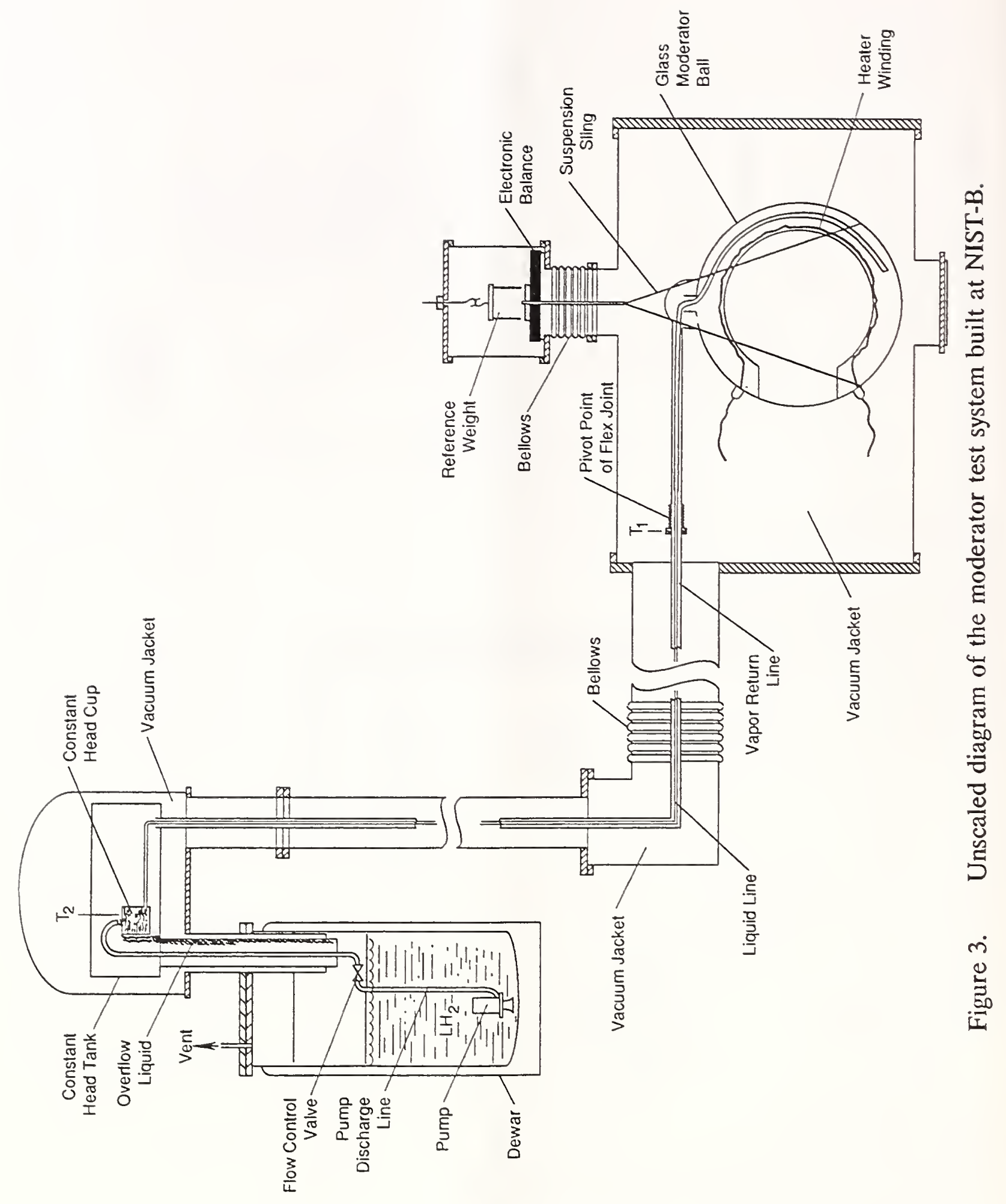




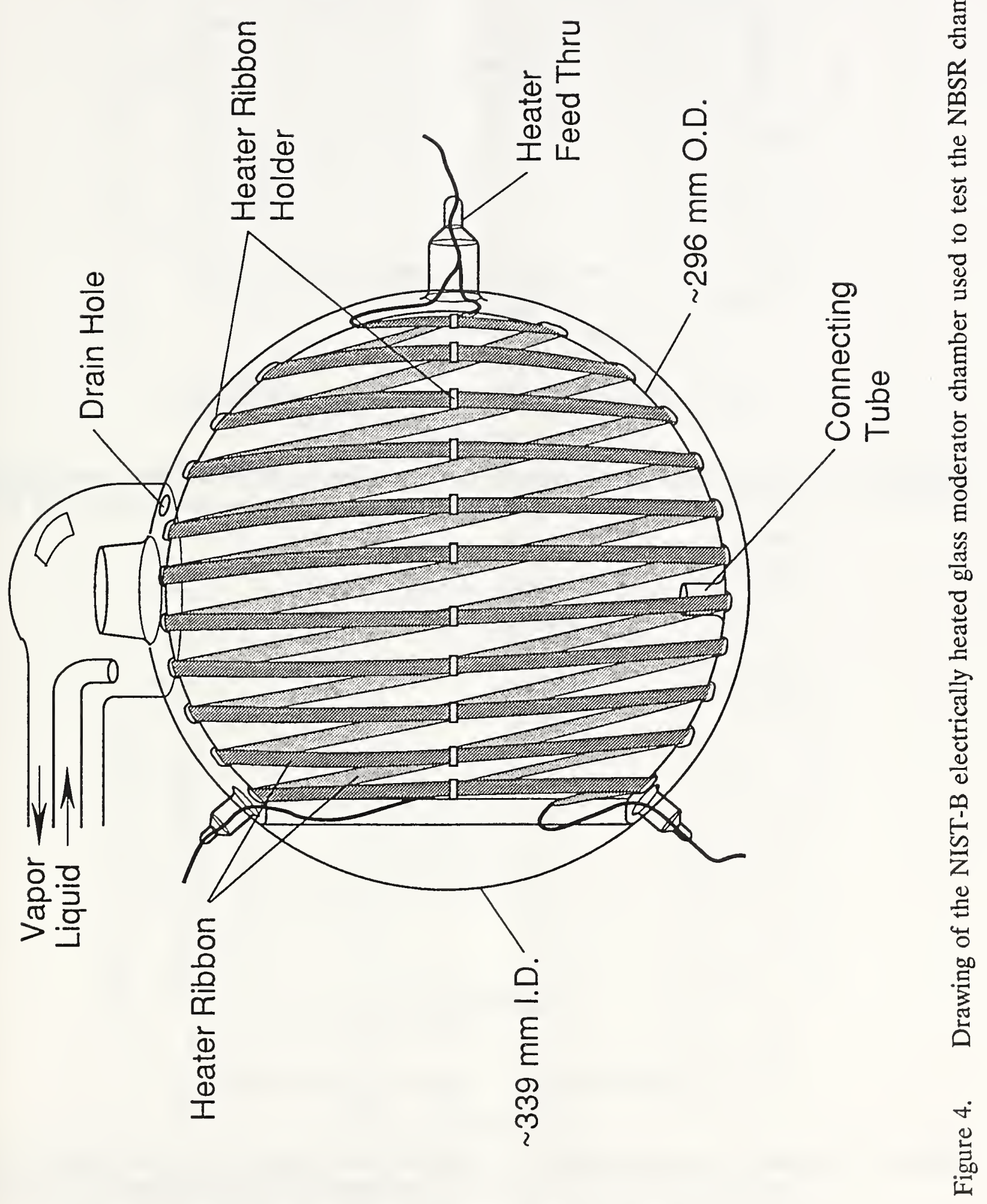




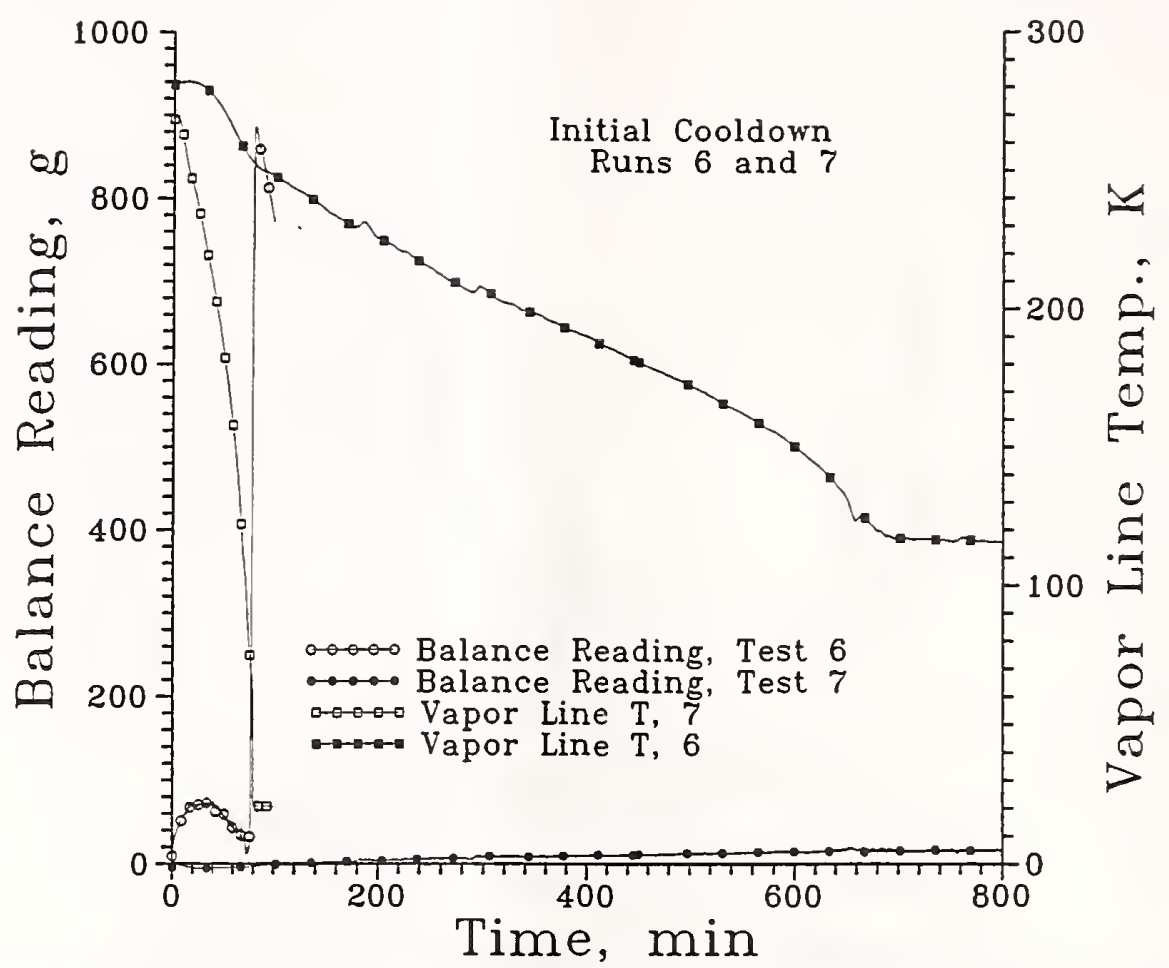

Figure 5. Balance reading ( $\mathrm{LH}_{2}$ mass uncorrected for zero shift and lever arm effects) and vapor line temperature for the start of two separate tests at $85 \mathrm{kPa}$ pressure.

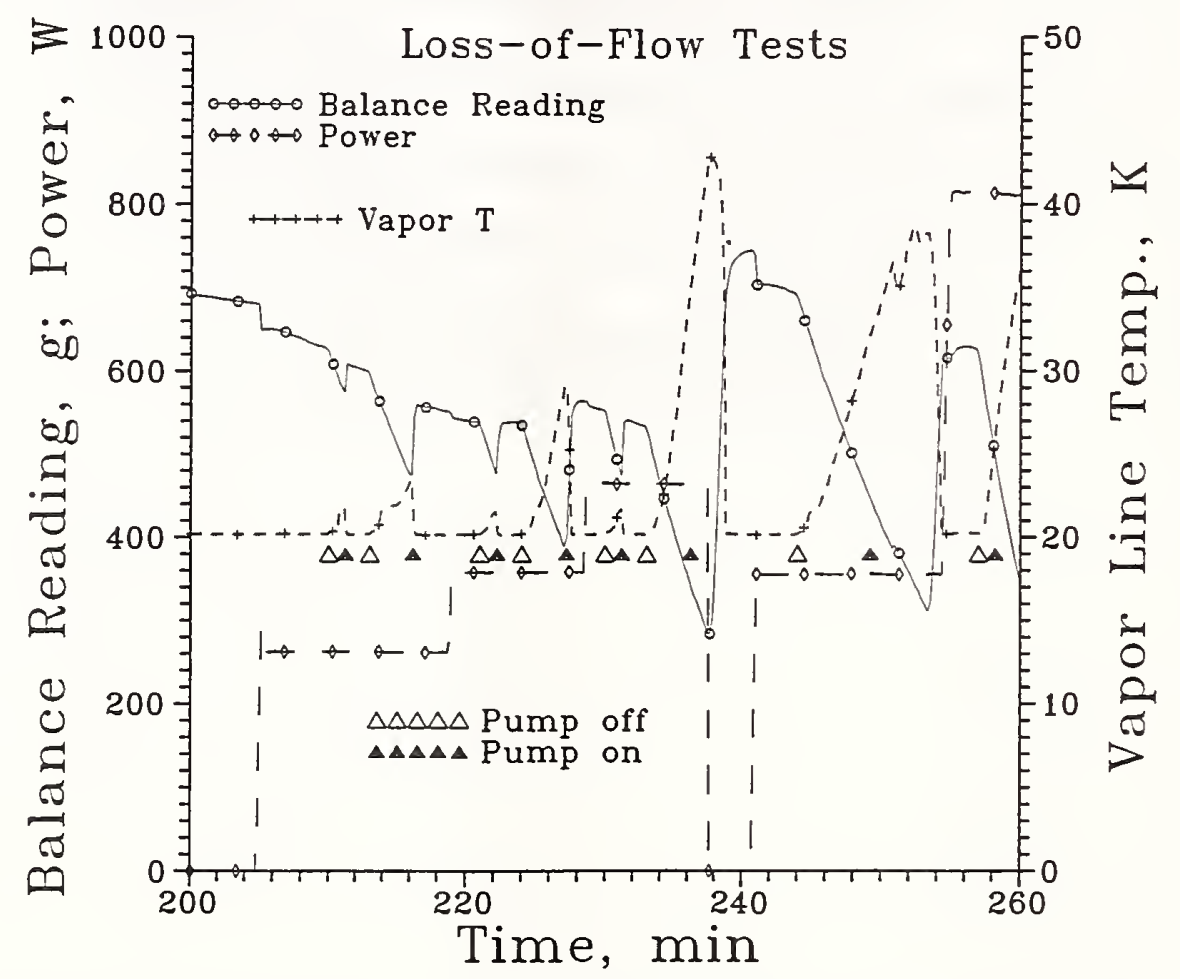

Figure 6. Balance reading, power to the chamber and the vapor line temperature as a function of time for test 7 at $85 \mathrm{kPa}$ pressure. The open triangles mark the inflow stop times, the solid triangles mark the inflow restart times. 


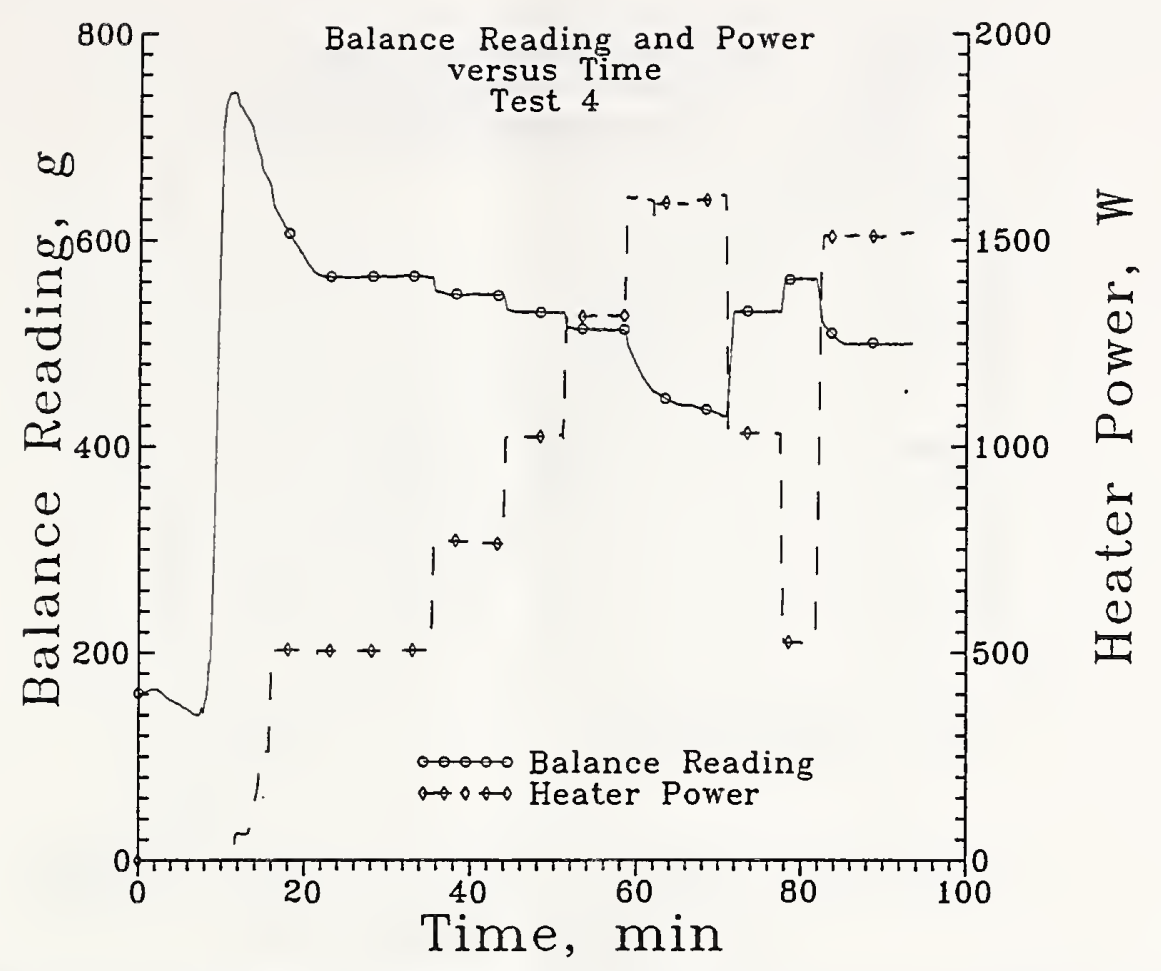

Figure 7. Test 4 showing the balance reading as a function of time at the power levels shown and $85 \mathrm{kPa}$ pressure.

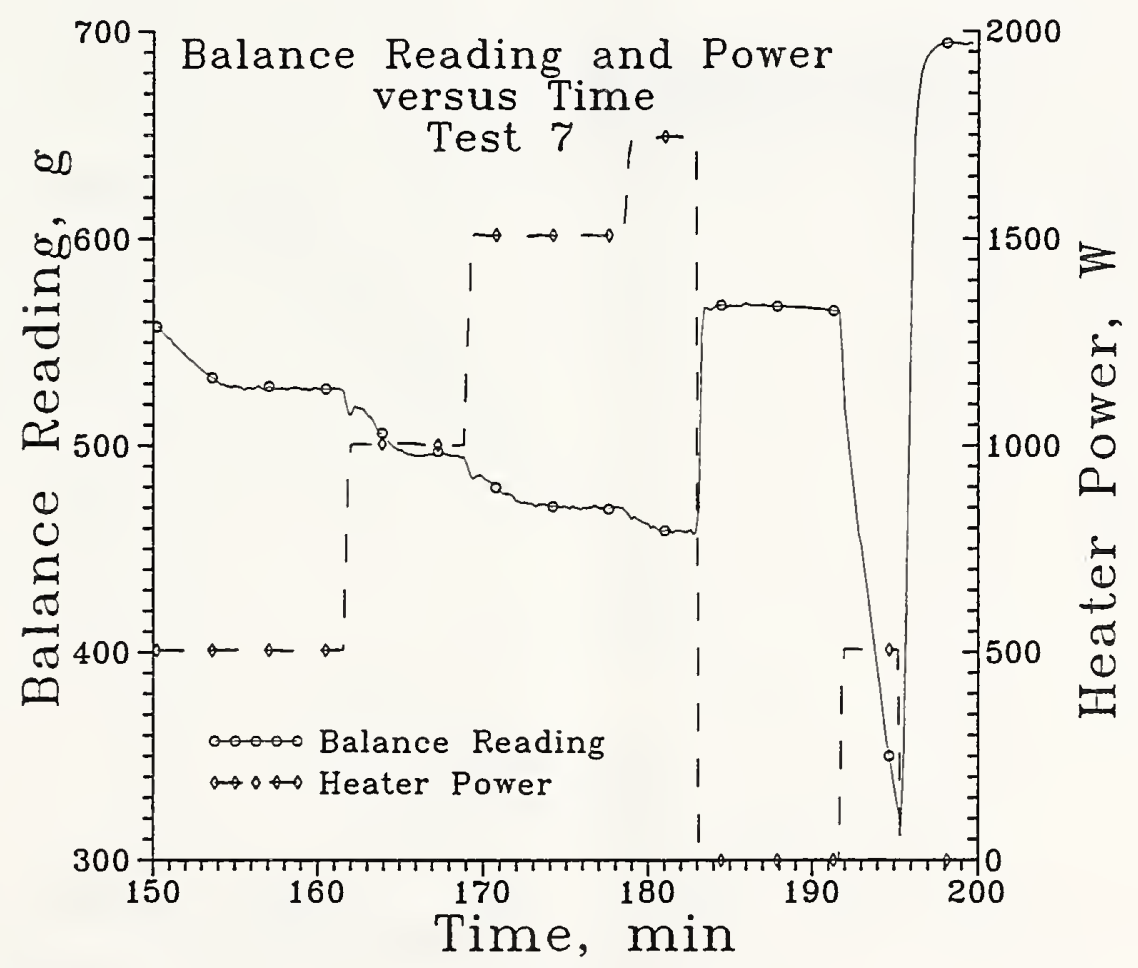

Figure 8. Test 7 results showing the balance reading as a function of time for several powers at $85 \mathrm{kPa}$ pressure. 


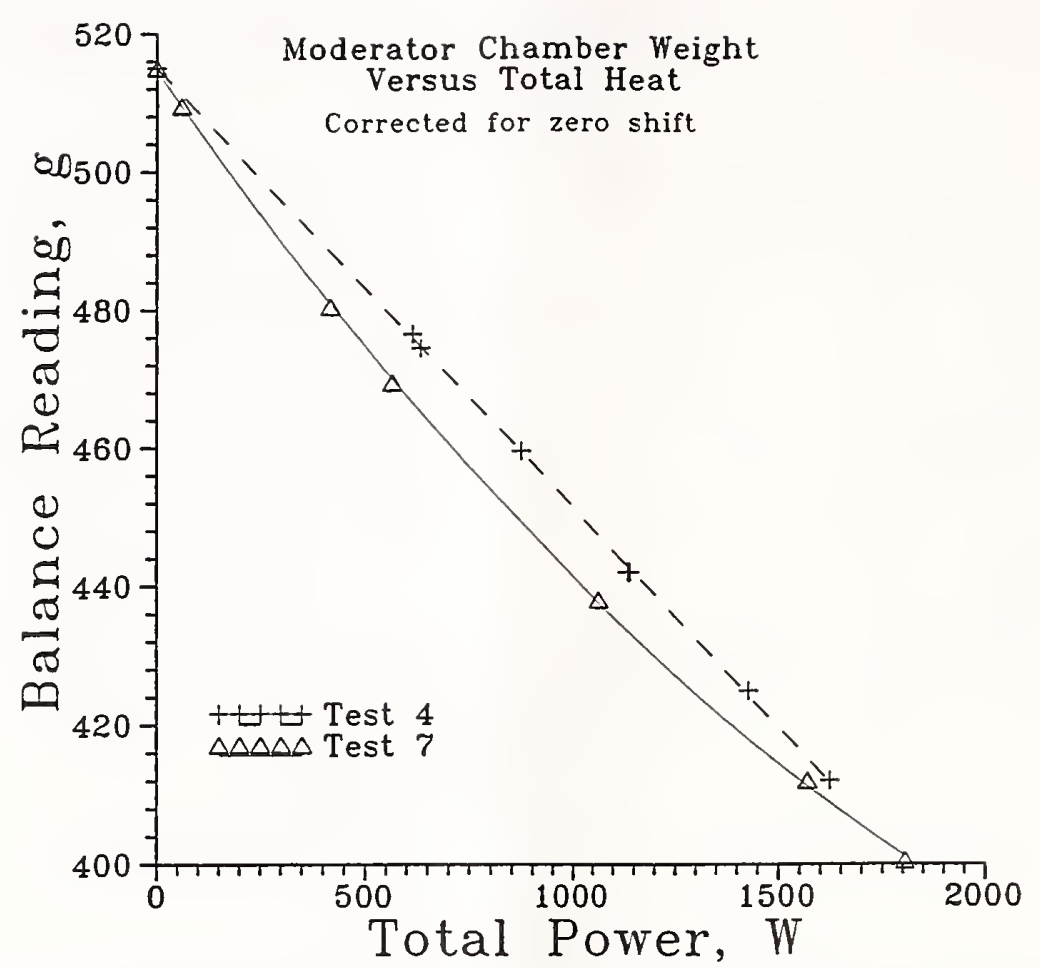

Figure 9. Balance reading corrected for zero shift for tests 4 and 7 at $85 \mathrm{kPa}$ pressure.

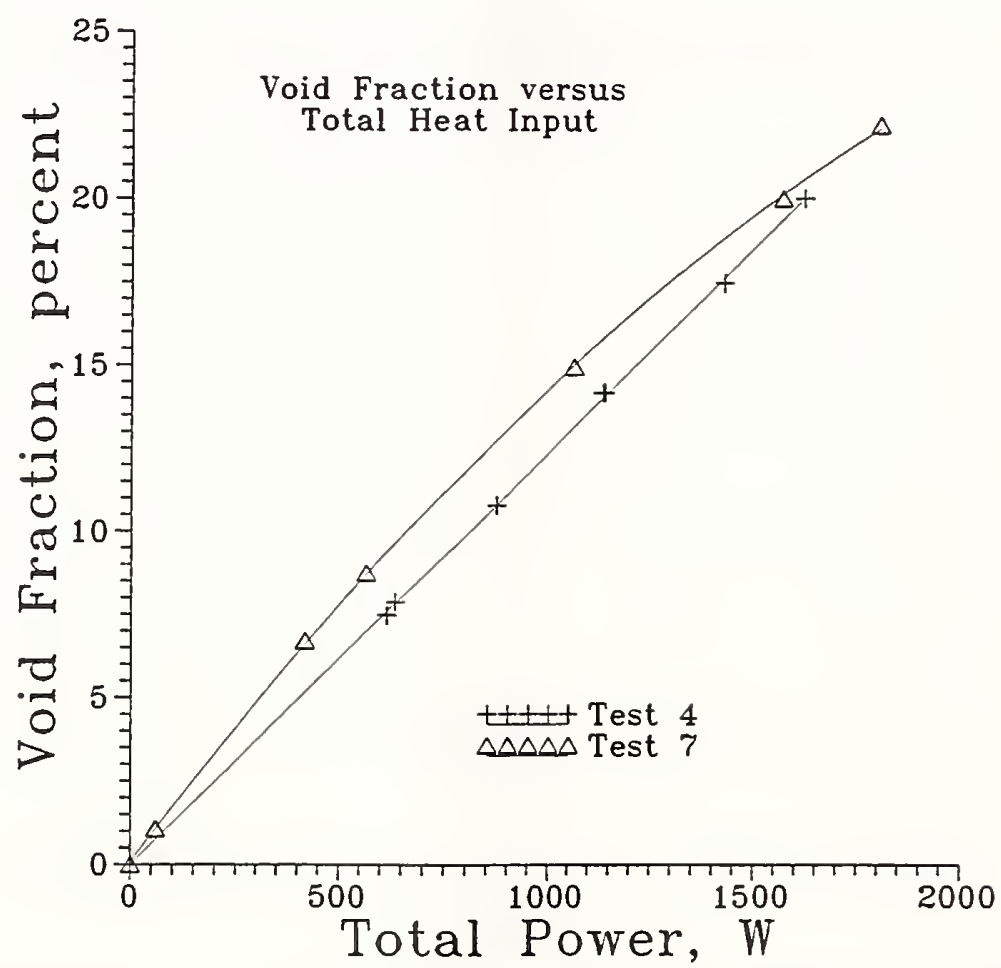

Figure 10. Void fraction as a function of power to the moderator chamber for tests 4 and 7 at $85 \mathrm{kPa}$ pressure. 


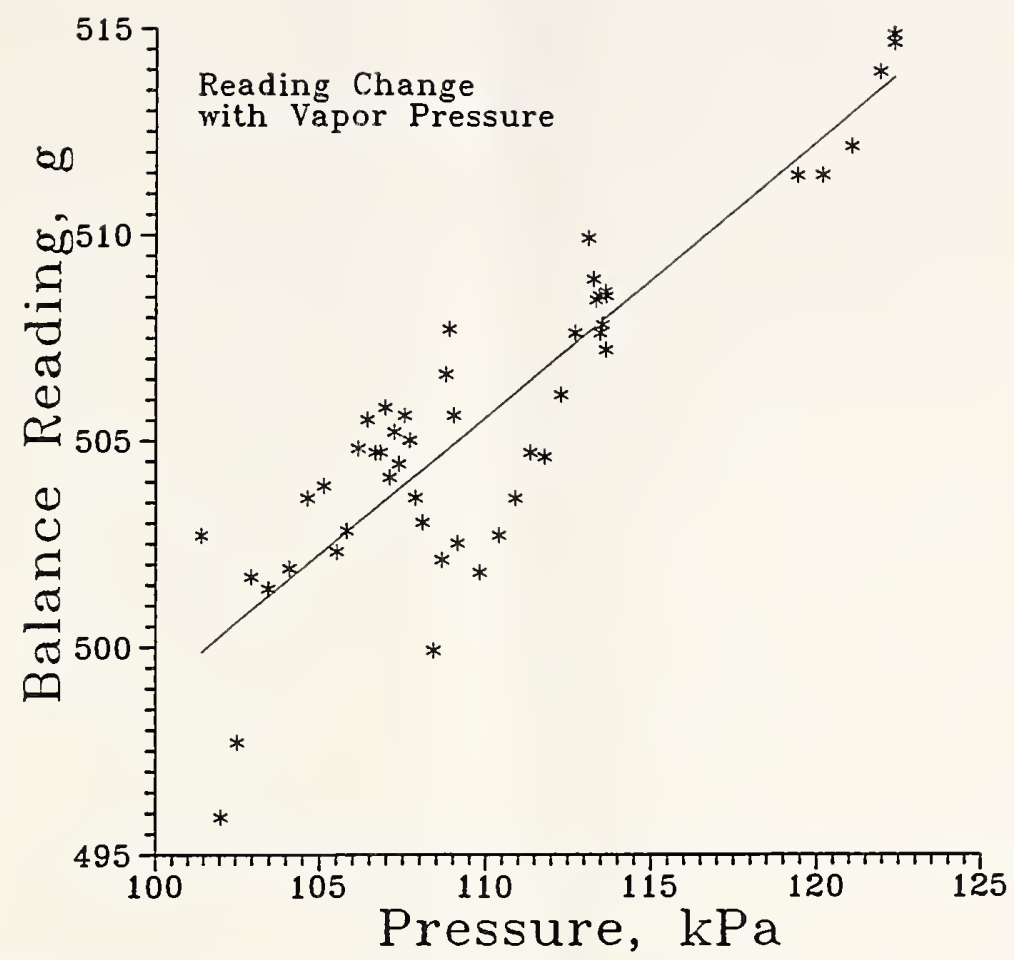

Figure 11. Chamber mass as a function of pressure for decreasing pressure at $860 \mathrm{~W}$ total input power.

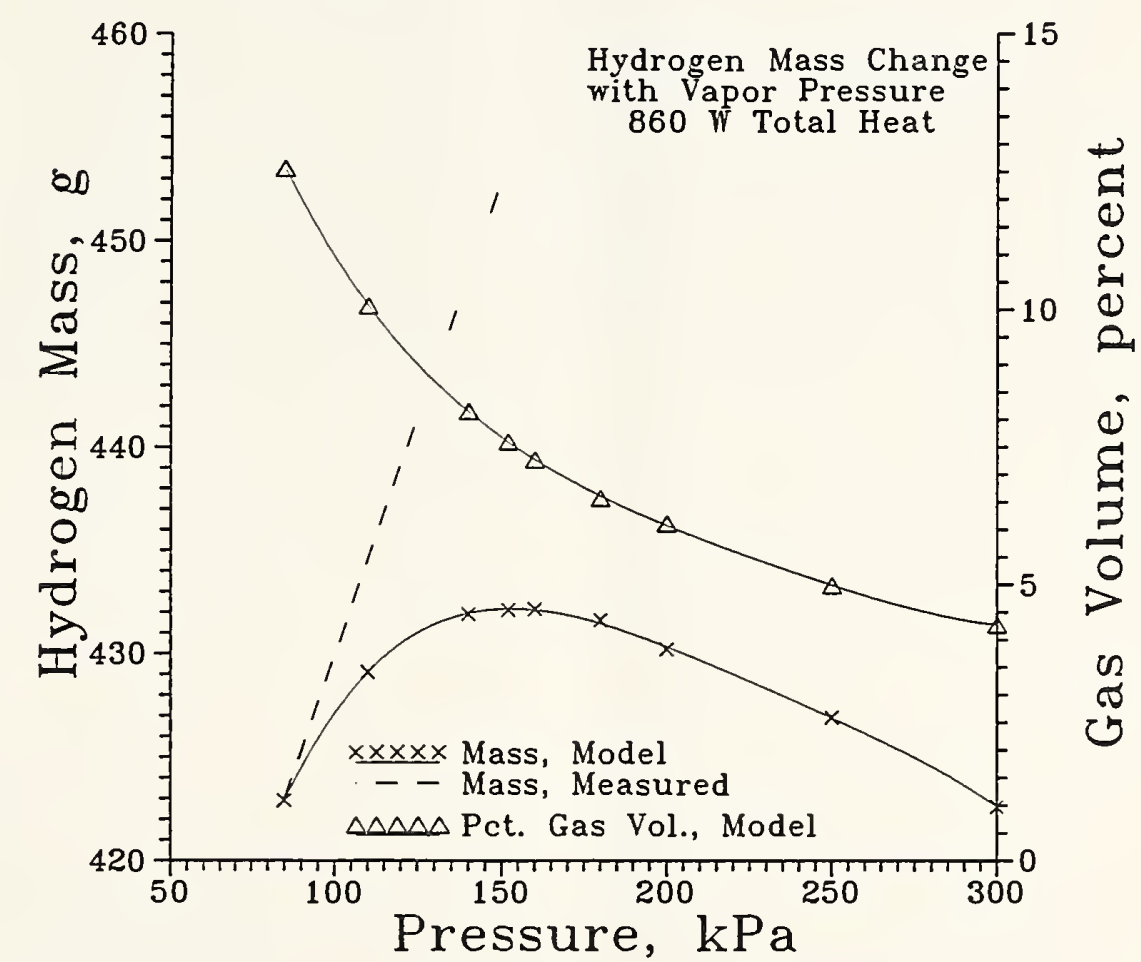

Figure 12. Hydrogen mass and gas volume predicted from model as a function of pressure at $860 \mathrm{~W}$ heat input. Data correlation of Experiment 8 shown for comparison. 


